\title{
Culinary practices: preparation techniques and consumption of Basotho cereal breads in Lesotho
}

\author{
Pulane Nkhabutlane ${ }^{1,2^{*}} \mathbb{D}$, Henriëtte L. de Kock ${ }^{1}$ and Gerrie E. du Rand
}

\begin{abstract}
Lesotho is a small country (30,350 sq.km with about 2.233 million population), completely surrounded by the Republic of South Africa. The people of the Kingdom of Lesotho are referred to as Basotho. This study aimed to investigate the culinary practices with regard to traditional Basotho bread, thus serving as a basis for documenting an aspect of Basotho traditional food knowledge. The study was conducted in five districts of Lesotho using focus groups, each consisting of ten housewives in each district, and face-to-face interviews with 253 women respondents who completed a questionnaire related to their knowledge, preparation and consumption of traditional Basotho bread. Recipes for ten traditional Basotho breads were obtained during five focus group sessions. The survey revealed that most of the respondents (99\%) prepare bread at a household level using wheat flour. A few (15\%) use maize flour and sorghum flour is used by only (5\%). The main preparation steps were identified as sorting, cleaning of grains, dry milling and/or wet milling, mixing ingredients, fermentation and cooking. Bread is used for household consumption and social functions, such as weddings and funerals. This paper documents the culinary practices for ten Basotho breads from maize, wheat and sorghum. Research geared to the improvement of the quality characteristics of maize and sorghum breads should be given the highest priority to encourage the use of local ingredients.
\end{abstract}

Keywords: Culinary practices, Traditional Basotho bread

\section{Introduction}

Lesotho is divided into ten districts that lie within two distinct geographical areas referred to as the highlands that are predominantly rural and the lowlands where the main urban centres are located. Climatic conditions vary considerably between these two regions with summers generally hot $\left(30^{\circ} \mathrm{C} ; 86^{\circ} \mathrm{F}\right)$, yet many places have very cold winters. The lowlands can be as cold as $-7{ }^{\circ} \mathrm{C}$ $\left(19.4{ }^{\circ} \mathrm{F}\right)$ and the highlands $-20{ }^{\circ} \mathrm{C}\left(-4.0{ }^{\circ} \mathrm{F}\right)$ at times. Lesotho is very high in altitude, about $3500 \mathrm{~m}(11,500$ $\mathrm{ft}$ ) above sea level at the highest points in the mountainous areas and almost $1200-1400 \mathrm{~m}(4000-4600 \mathrm{ft})$ in the low-lying areas [1]. The people of the kingdom of Lesotho are referred to as Basotho, and the official languages are Sesotho and English.

\footnotetext{
* Correspondence: pn111@hotmail.com; p.nkhabutlane@nul.Is

${ }^{1}$ Department of Consumer and Food Sciences, Faculty of Natural and Agricultural Sciences, University of Pretoria, Private Bag X20, Hatfield 0028, South Africa

${ }^{2}$ The National University of Lesotho, P.O. Roma, Roma 180, Lesotho
}

In Lesotho, traditional bread (bohobe) is a general term that covers different types of cereal (maize, wheat, and sorghum) meal dumplings (linkhoa). The formula for Basotho bread is basically flour, a starter culture, salt and water. Basotho favour the characteristics of bread and perceive bread as the most important and tastiest food compared to all other cereal products. Bread prepared from wheat is preferred more than maize and sorghum bread by Basotho. The benefits associated with the use of maize and sorghum in Lesotho for bread making is due to the declining wheat production in recent years. It is evident that the consumption of wheat bread becomes very costly and cannot be afforded by poor families [2]. The use of sorghum and maize on their own or through compositing them with wheat as traditionally practiced by Basotho could reduce bread costs and provide basic nutrients to underprivileged Basotho. Bread in Lesotho is consumed mainly for its energy supply to enable Basotho to perform their heavy daily duties. However, the main differences in the nutritional composition

(c) The Author(s). 2019 Open Access This article is distributed under the terms of the Creative Commons Attribution 4.0 International License (http://creativecommons.org/licenses/by/4.0/), which permits unrestricted use, distribution, and 
of breads are due to the differences in grains and the type of flour used. For example, bread in which commercial flour is used generally has higher energy values than their whole grain flour counterparts which are rich in fibre.

Food practices are embedded in culture and every culture has specifications pointing to the hedonic characteristics of food such as taste, appearance, flavour and aroma, which are determined by the context in which the food is selected or consumed [3]. Consumption of traditional Basotho breads differ according to two major cultural groups, according to the cultural hedonic context (higher context cultures and lower context cultures) which coexist in Lesotho. They are identified as the rural and old generation representing the higher context cultures and the urban and younger generation representing the lower context cultures [3]. The differences of cultures are due to previous experience, socio-economic status, physiological status and liking of sour taste. Old people like sour taste better than the young generation, because younger participants are less familiar with maize and sorghum breads than they are with wheat breads. Unfamiliarity with the sensory attributes of these products contributes to their lower acceptance. The older participants are familiar with all traditional breads and value them for use in the important Basotho cultural ceremonies. The movement from the rural areas to urban areas has also changed the traditional bread practices to modern westernised ways. This therefore placed Lesotho into both the higher and lower cultural hedonic contexts such that rural and old people are higher context cultures and urban and younger people are lower context cultures.

Family structure is also an important part of Basotho culture. It determines the context in which food is consumed. In Lesotho, the type and amount of bread prepared in the household is determined by the composition of their household. With more men and boys in a household, the amount prepared would be higher. Basotho men eat large quantities of food in order to have energy for tasks such as ploughing, cutting trees for wood or building animal kraals. The size of the family also determines bread acceptance, as larger families turn to enjoy bread and eat more of it than small families in Lesotho, and other cultural issues surrounding bread acceptance is the number of meals served in Basotho households. Only two meals are traditionally served and the same practice is still followed in the rural areas. This means that large quantities of bread served in the morning are meant to provide energy for a longer period of the day until the next last meal of the day that is served in the evening [4].

In Africa, the traditional ways of preparing, cooking and serving foods have been passed on from one generation to the next without or with very limited documentation [5]. In many African societies, the transfer of knowledge takes place through oral communication and through informal learning of traditional practices. In this regard, cultures are losing their originality of cuisines through an unrecorded past in written form [5]. The loss of traditional food knowledge could negatively impact dietary diversity, culturerelated food activities, socio-economic conditions, health status, cultural integrity and general quality of life $[6,7]$. Documentation of culinary practices could promote the use of local ingredients to prepare foods that reflect ethnicity and environmental well-being. Thus, the overall aim of this study was to investigate the culinary practices of Basotho with regard to traditional bread, to characterise breads and to apply the cultural hedonic framework to describe consumers' perceptions about the acceptance of traditional Basotho breads.

\section{Methods}

The study was descriptive and exploratory in nature. The mixed methodology convergent parallel design [8, 9] employing both qualitative and quantitative techniques was used. Five focus group sessions were held and a structured questionnaire was completed. The investigation was conducted in five districts of Lesotho (Leribe, Mafeteng and Maseru represented urban areas and Mokhotlong and Thaba-Tseka represented rural areas). Data collection was done in stages and five days were spent in each district.

Chiefs and the nutrition extension officers of the regions assisted in recruitment of participants by arranging meetings in central places (church buildings, chief's places and government offices). Purposive sampling identified participants based on accessibility, that they were Basotho women born and raised in the district, knowledgeable about and regular consumers of, traditional Basotho breads, older than 25 years and willing to participate. A total of 253 respondents $(n \pm 50$ from each region) completed a face to face questionnaire which covered aspects related to knowledge about traditional Basotho bread, frequency of consumption and bread storage. Focus groups, one in each district, consisting of $n=10$ housewives, involved demonstrations of preparation and cooking of traditional breads and describing their qualities. The decision to have ten people in each group was made on the basis that there were ten traditional breads to be demonstrated, and each participant demonstrated one traditional bread in which she was an expert. The main questions in the focus groups included aspects on ingredients used for preparing different kinds of traditional Basotho breads, equipment used, preparation, cooking and serving procedures, perception of sensory qualities, beliefs and symbolic values of bread in Basotho culture. Video, photographing and note taking captured focus group data. Both the 
questionnaire and the focus group guide were pilot tested by a group of Basotho women working in Pretoria, South Africa. Both questionnaire and focus groups were conducted in Sesotho (language spoken by Basotho) between March and April 2011.

The quantitative data was analysed using $\mathrm{SAS}^{\circ}$ version 9.3 (SAS Institute INC, SAS campus Drive, Cary, NC 27513) under Microsoft Windows XP (SP3). Focus group data was transcribed immediately after data collection, and an inductive grounded theory approach was used to 'break up' the data into codes and themes $[10,11]$.

\section{Results and discussion}

Focus group participants identified and demonstrated ten types of breads prepared by Basotho (Table 1).

\section{Wheat-based breads}

Steamed wheat bread (leqebekoane), baked wheat bread (bohobe ba polata) and pot-roasted wheat bread (liphaphatha) are traditional Basotho breads prepared from wheat flour, sourdough or commercial yeast, salt and warm water. The dough preparation is the same for all the three breads, but the difference comes from the cooking methods. Flour is mixed with salt, starter culture and sometimes sugar. One participant in Leribe district ( 83 years old) commented:

Lesotho does not have sugar cane; we do not understand why Basotho nowadays like to add sugar in bread. Sugar is not part of Basotho ingredients.

And another participant in Thaba-Bosiu (55 years old) said:

Sugar is optional in bread making. Basotho used to prepare bread without any sugar, because whole wheat flour can produce sweet-tasting bread on its own.

Warm water is added to all the ingredients and kneading continues until the housewife is satisfied with the signs of a well-developed dough. The dough is then covered and left to ferment. Signs indicating that wheat dough is well-fermented include as follows: double the size of the dough, bubbles and sour smell. According to participants, an experienced housewife would easily detect the weight differences between fermented and unfermented dough. The fermented dough would be lighter than the unfermented dough. The Egyptians around $7000 \mathrm{BC}$ were preparing unleavened bread from stone-ground cereals. Around $3500 \mathrm{BC}$, the Egyptians discovered that if dough was left unattended for several hours before baking, it became airy and lighter than the freshly made dough because of the $\mathrm{CO}_{2}$ produced during fermentation by natural yeasts [12]. Participants mentioned that wheat bread made from dehulled grains (refined flour) would have a relatively higher volume and thus be less dense and softer than bread from whole undehulled wheat flour.

\section{Steamed wheat bread (Leqebekoane)}

Focus groups revealed that steamed wheat bread is cooked in a three-legged iron pot in rural areas or in a big pot over a paraffin or gas stove in urban areas. The dough is shaped into round balls (linkhoa) and placed over the prepared steamer (Fig. 1). The pot is then filled with water up to the level of the steamer and left to boil prior to adding the dough. Bread is allowed to steam in a pot covered throughout the process, but water may be replenished as needed.

Participants described traditional steamed wheat bread as round and/or oblong in shape, with a soft thin skin that forms a smooth semi-glossy finish without a crust. Wheat bread should have a high volume, with welldistributed air cells. The texture varies from soft (commercial refined wheat flour) to heavy (locally milled whole wheat). Moist, dense and airy texture were perceived as typical characteristics of steamed wheat bread. Other researchers reported similar properties of steamed wheat bread in other cultures [13-18]. The colour of steamed wheat bread was reported to depend on the type of wheat flour used. The cultivated wheat produces dark, and sometimes golden, brown bread especially from dehulled wheat. Commercial wheat flour produces a greyish and light brown bread with well-distributed specks of bran inside and on the outside of bread.

Table 1 Classification of bread prepared in Lesotho

\begin{tabular}{llll}
\hline Types of breads & & & \\
\hline Wheat-based breads & Maize-based breads & Sorghum-based breads & Composite breads \\
\hline Steamed wheat bread (Leqebekoane) & $\begin{array}{l}\text { Dry maize bread (Monepola oa poone } \\
\text { ea thooko) }\end{array}$ & Dry sorghum bread (Ntsoanatsike) & $\begin{array}{l}\text { Wheat + maize bread } \\
\text { (Mochahlama oa poone) }\end{array}$ \\
Baked wheat bread (Bohobe ba polata) & $\begin{array}{l}\text { Green melie bread (Monepola oa poone } \\
\text { e ncha) }\end{array}$ & Green sorghum bread (Senkhoana) & Wheat + sorghum bread \\
(Mochahlama oa mabele) & & \\
Pot roasted bread (Liphaphatha) & $\begin{array}{l}\text { Pre-cooked maize flour bread (Mochahlama } \\
\text { oa poone } \\
\text { feela) }\end{array}$ & & \\
\hline
\end{tabular}




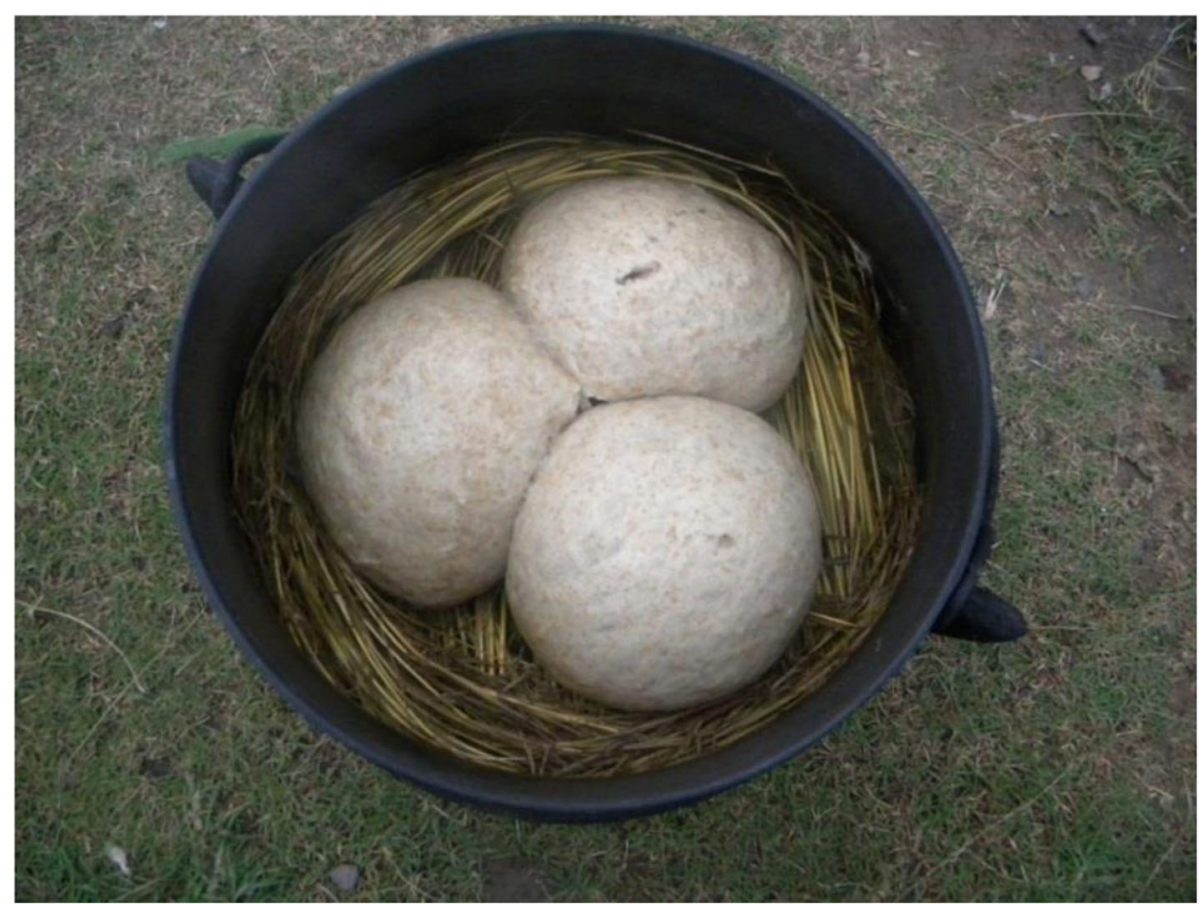

Fig. 1 Steamed Basotho wheat bread shaped into round balls (linkhoa). The bread is cooked over the steamer made from long grass (joang ba mohlomo). The grass is rolled in circles starting from the bottom of the pot up to the level that will allow dough to rise fully without touching the lid of the pot. The bread has to be removed from the steamer while still hot to prevent permanent sticking of grass on the bread. Basotho like the attractive print left by grass at the bottom of the bread. In order to use the steamer more than once, it is removed from the pot immediately, cleaned, dried and tied into a bundle for keeping it in a safe place such as hanging it on the tree

\section{Baked Basotho wheat bread (Bohobe ba polata)}

Baked Basotho wheat bread (bohobe ba polata) is cooked in a flat cast iron pot (pitsa ea polata) using coals from cow dung (lisu/likhapane). The fire is prepared well in advance and bread can only be baked when the coals are ready. The flat iron pot containing the dough was traditionally greased using animal fat (ts'otso). Nowadays, housewives grease the pot with cooking oil. The hot coals are placed on top of the lid and underneath the greased pot containing the dough (Fig. 2a, b).

The modern way of cooking traditional-baked wheat bread by urban people includes the use of a large aluminium pot on a paraffin heater or a paraffin or gas stove. Here, the challenge is that the heat only comes from underneath the pot and the upper side of the bread cannot be cooked unless the bread is turned during baking (Fig. 2c, d). To overcome this problem, participants in Mafeteng-Makaung demonstrated a combination method of cooking wheat bread whereby a small tin is filled with water and placed right at the centre of the pot just before putting the round balls of dough around it in a greased saucepan. During cooking, the water boils and provides steam to the top part of bread, while baking occurs at the bottom (Fig. 2e).
Baked wheat bread possesses similar quality characteristics as steamed wheat bread in volume, shape, crumb colour and crumb texture. Well-baked Basotho wheat bread must have a golden brown crust and an aroma of freshly baked wheat bread. The baked brown crust can be too hard for children and old people, unless dampened with plain or sweetened water and wrapped with a clean cloth while still hot.

\section{Pot-roasted breads (liphaphatha)}

Pot-roasted breads involve flattening the dough on a floured Basotho mat (sethebe) and cutting it into round, square or rectangle shapes, flattened in the palms of the hands to about 2 -cm thick, depending on the skill of the housewife or the cultural practice in different regions. The flattened pieces of dough are then allowed to rest and rise to its maximum size before it is roasted. The roasting is done on a hot surface of a pot or over the iron pot lid (Fig. 3). Sticking is prevented by sprinkling the roasting surface with a little flour.

Pot-roasted flat breads have a floury golden brown hard crust and a soft crumb. Immediately after cooking, the crust is dampened with a little water and wrapped with a clean cloth to soften. 


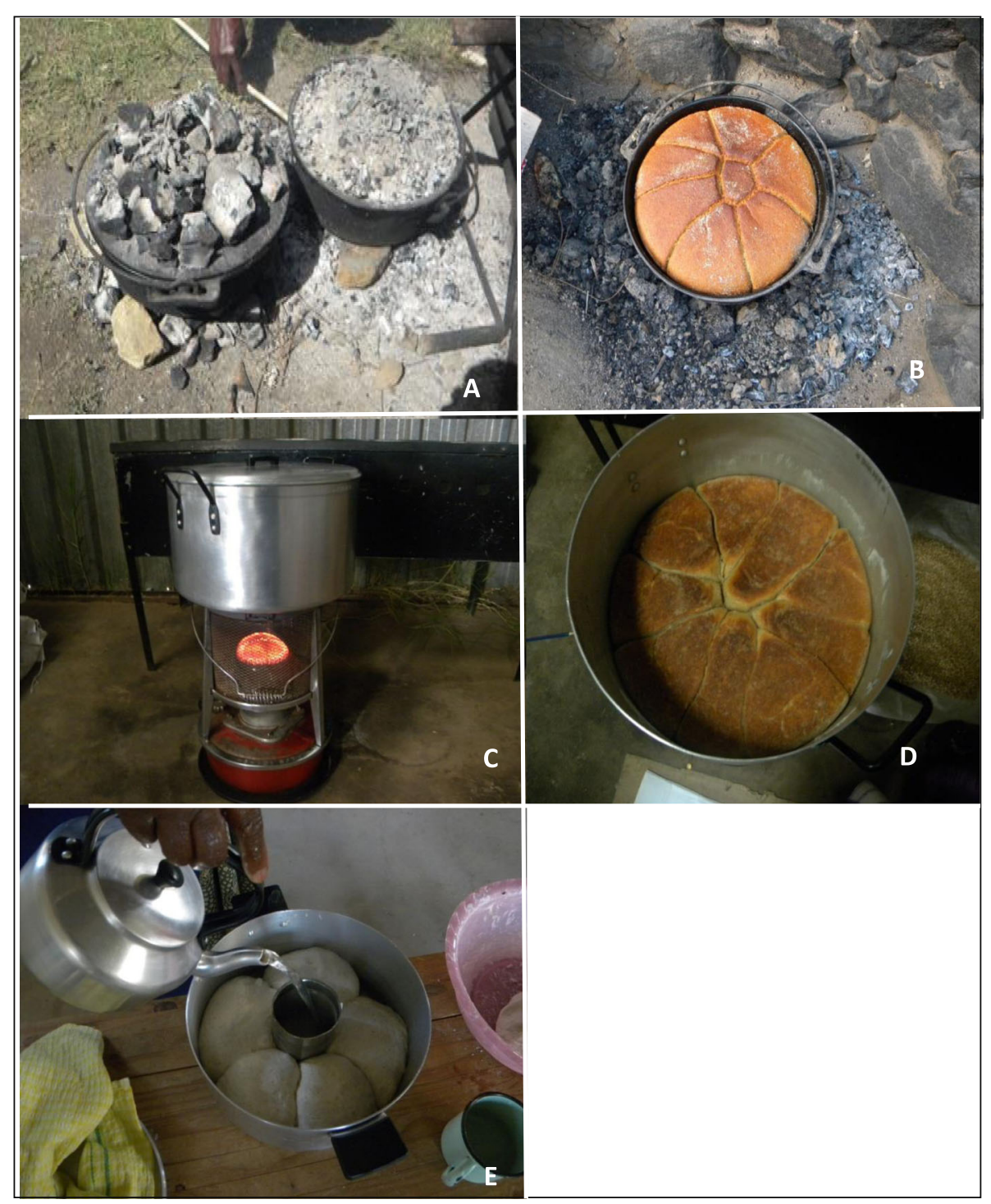

Fig. 2 Baked wheat bread: a Burning coals on a cast iron pot. The pot is placed on top of three well-chosen stones (litse'hetso) to enable distribution of coals underneath. $\mathbf{b}$ Baked bread inside a flat iron pot. c Baking using a saucepan on a paraffin heater. $\mathbf{d}$ Baked bread turned to cook the other side. e A combination method of baking and steaming. The baked bread was mostly used for special occasions, cultural celebrations and trips

\section{Maize breads}

\section{Green mealie bread (Monepla oa poone e ncha)}

Green mealie (maize/corn) bread is prepared in autumn when housewives are waiting for their maize crops to dry out in the fields. The preparation involves wet milling green mealie kernels to a thick dough on a grinding stone and adding a little salt for taste. The dough is shaped into cob-like shapes and covered with maize leaves/husks. The covered dough is then placed over the steamer and allowed to steam until completely cooked. Three names for this bread were noted in different regions as 'Malitsibana, which means feather-like appearance; mohlefe, which means very fibrous; and monepola oa poone e ncha, which means wet-milled green mealie bread.

Participants described the qualities of green mealie bread as whitish or yellowish depending on the variety of maize used. The texture qualities include heavy, compact and fibrous. The bread is well liked for its quick satiating value and the intense green maize aroma. Participants who had not eaten this bread expressed the desire to prepare it in their households, one of them (a 31-year-old woman) said: 


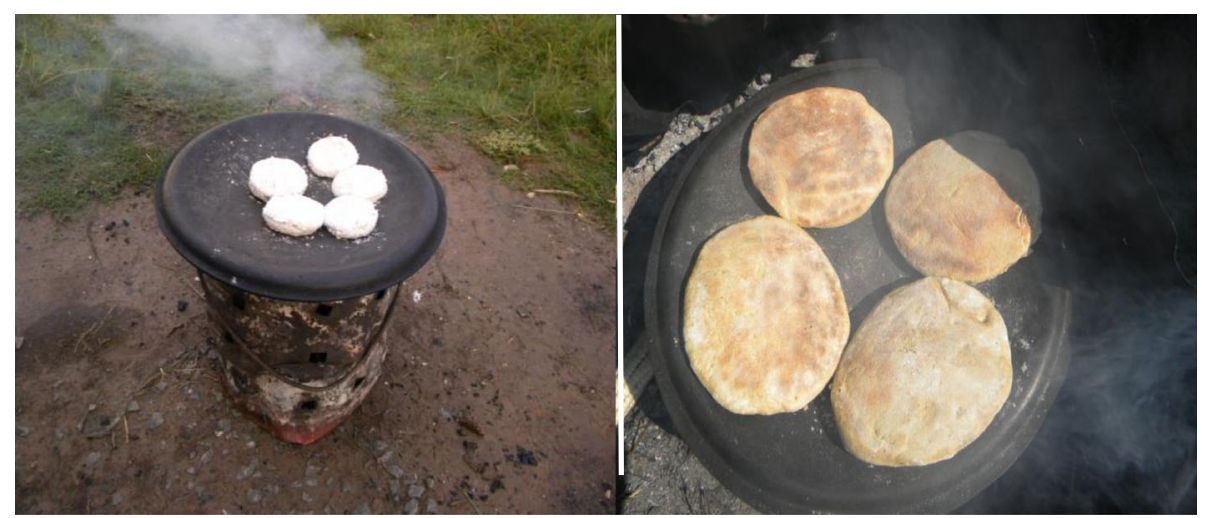

Fig. 3 Pot roasted wheat bread cooked on the inside surface of iron pot lid. The hot surface used for roasting is sprinkled with a little flour and is not greased. Roasted breads are cooked at the bottom side first and have to be turned, in order to brown both sides. Basotho used this bread as provision for long trips due to its long shelf life and light weight

I like this bread although I have not eaten it before. It tastes like green mealies, I am going to cook it in my household and I just hope my children will like it.

\section{Dry maize bread (Monepola oa poone ea thooko; o kh'afotsoeng and o haitsoeng)}

During the preparation of dry maize bread, cleaned dry maize kernels are soaked to soften the pericarp, the wet maize is then crushed on a grinding stone and this process is referred to as ho-kh'afola by the Basotho. The loose bran is further removed by hand when the crushed maize meal is shaken several times (ho-hlokola) in a bowl. The remaining gritty maize meal is mixed with warm water and allowed to soften for $2-3 \mathrm{~h}$ prior to wet milling. Alternatively, to prepare monepola oa poone ea thooko o haitsoeng, the dry maize kernels are coarsely ground on a grinding stone and then mixed with water to soften in order to facilitate wet milling.

The wet milled dough is divided into two equal parts. The first half is moulded into small rectangular shapes that are steamed over the steamer for 10 min to pre-cook the starch. The steamed mixture is then mixed with the remaining half and kneaded to form a sticky dough. In this case, the steamed mixture is a binding substance to enhance the moulding of maize dough into balls. In Ghana, a similar type of bread is prepared [19-22].

The starter culture is then added and the dough allowed to ferment overnight or for about 8-9 h depending on the level of sourness desired. The fermented dough is moulded into balls and steamed using the traditional steamer. Apart from sourness, the fermented maize dough will have both large and small cracks depending on the consistency of the dough, indicating that the dough is well fermented.

The remaining raw dough is sprinkled on top of the steaming dough and allowed to cook. Sprinkling is continued at intervals, until all the raw dough is finished. The pot is covered and bread is cooked until all the water has evaporated. When the bread is fully cooked, the steamer is removed and the bread is allowed to drop into the pot to be completely stirred using a wooden stick (lesokoana). The stirred maize bread is then rolled on a grinding stone to a smooth round ball (polokoe) and it is ready to be served. A good quality polokoe should be smooth without cracks (Fig. 4). The preparation of polokoe is regarded as a skill on which a newly married woman is tested. This test enables her in-laws to get an impression of her upbringing and is an indication of whether she will be able to take care of the family or not. An alternative is to mould the dough into round balls as soon as it has fermented, as is done in the case of steamed wheat bread.

The colour of monepola oa poone ea thooko was described as greyish white or yellowish white depending on the maize variety used and handling during preparation. This bread is preferably served with both fresh and sour milk. In general, monepola oa poone ea thooko is heavy, and very dense, depending on the milling skill of the housewife [23]. The bread texture also varies from fine to coarse, but it should not be crumbly or sticky. However, the sour taste in monepola oa poone ea thooko is considered its most important sensory attribute.

\section{Pre-heated dry maize bread (Mochahlama oa poone feela)}

Mochahlama oa poone feela is a fermented bread prepared from dry maize meal. Boiling water is added to maize meal and the mixture is left covered until it cools. The starter and salt are added to the cool mixture and mixed by hand to form a dough that is allowed to ferment until it is sour. The fermented dough is cooked using steaming, as described for the steamed wheat bread. 


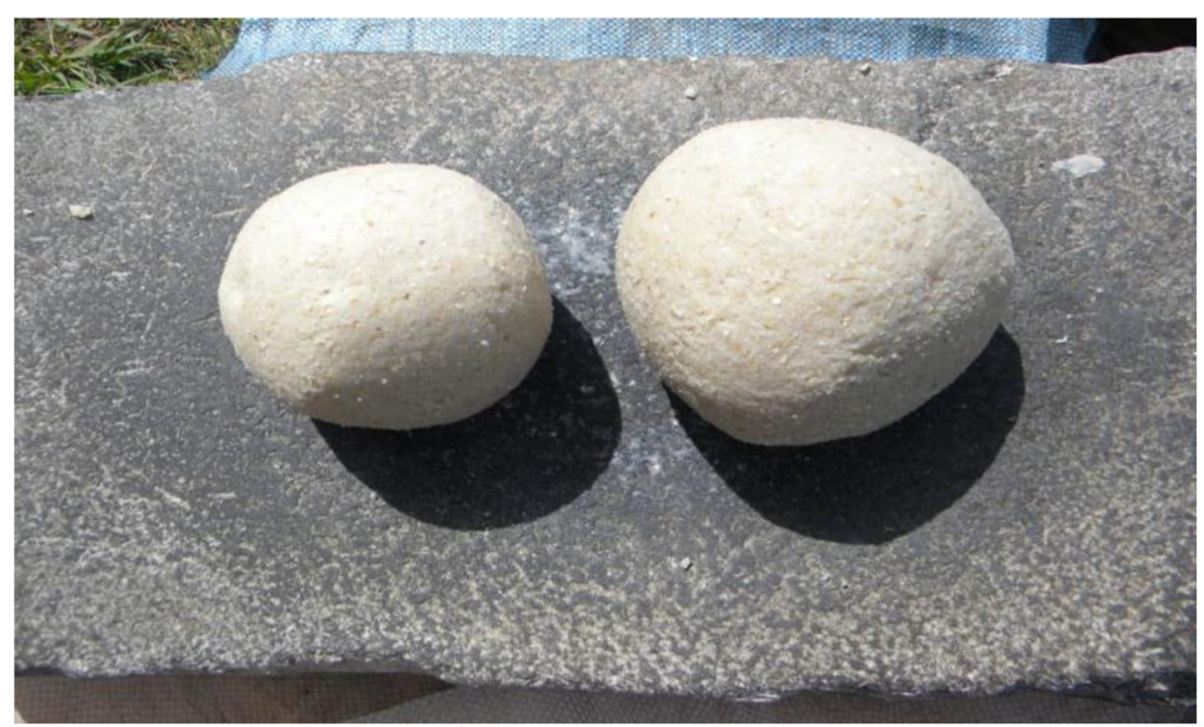

Fig 4 Dry maize bread shaped into a smooth round ball (polokoe). The moulding of these bread balls is done on a clean grinding stone that was used for wetmilling the dough to prepare the bread. The size of the balls differ according to the preference and the skill of the housewife. The bread was preferred by Basotho for its heavy texture which created long satiety enabling them to carry heavy duties before the next meal.

\section{Sorghum-based breads}

Two versions of bread are prepared from sorghum meal, green sorghum bread (senkhoana) and dry sorghum bread (Ntsoanatsike).

\section{Green sorghum bread (Senkhoana)}

Senkhoana is also shaped into a polokoe as is done in monepola oa poone ea thooko. Senkhoana is prepared from green sorghum. Green sorghum bread is associated with poverty, because housewives said eating senkhoana is not a matter of choice but only to satisfy hunger. One participant (a 58-year old in Mokhotlong) clearly narrated this fact:

Senkhoana has always been part of my diet and I still consume it even today. I have never worked before, and I have many children whose father (my husband) has abandoned.

Participants described the colour of senkhoana as varying from greenish, greyish, to reddish brown depending on the variety and stage of maturity of the sorghum. Senkhoana is slightly bitter, and it is best eaten with milk or meat stew. The texture of senkhoana is very cohesive and therefore heavy. For elderly participants of the focus groups who had eaten senkhoana before, it was a reminiscent of the 'good old days'. Younger women who had not tasted senkhoana before did not like its colour, texture or taste. One participant (a 28-year-old woman) described the feeling she had with a piece of senkhoana in her mouth:
It is very sticky in the mouth and it takes long to chew, I am not able to swallow this bread. I have never eaten this bread before and I do not think I will cook it for my family.

\section{Dry sorghum bread (Ntsoanatsike)}

Ntsoanatsike is made from dry sorghum grains. The preparation steps for ntsoanatsike are similar to the dry maize bread (monepola oa poone ea thooko) as described previously. Similar bread in Northern Ghana, kenkey, is sometimes prepared using sorghum instead of maize [19, 20].

The most important characteristic that determines a good quality ntsoanatsike is sour taste. This bread is very dark, and the colour ranges from reddish brown, brown to greyish brown, also depending on whether red or white sorghum has been used. The Pedi in South Africa also prepared a similar type of dumpling with sorghum [24].

\section{Composite breads (mochahlama)}

In many cases, Basotho prepare breads from a mixture of wheat and maize or wheat and sorghum in order to overcome the high cost of wheat flour. According to the participants, composite breads are also associated with poverty.

\section{Composite maize/wheat and sorghum/wheat bread (mochahlama)}

Mochahlama is a steamed fermented bread prepared from either a composite of maize and wheat or sorghum 
and wheat flour. The preparation involves heating maize or sorghum flour with boiling water and keeping it covered for about $10 \mathrm{~min}$ to cook the starch and to allow the development of a sweet taste, then the mixture is cooled. The pre-heating also helps to reduce crumbliness in the composite bread.

The resulting dough is mixed with wheat flour, salt and a starter culture and allowed to ferment. Fermented composite dough cracks and has a more intense sour smell and sour tastes than wheat dough. The fermented dough is cooked using the steaming method only. The other methods of cooking are said to produce composite bread with a very dry and hard texture.

Characteristics of mochahlama include a sharp sour taste and a blend of salt and sweet taste. Composite breads have a relatively large volume and a round shape. Wheat and white maize composite bread is whitish brown with visible brown fibrous material from the wheat flour. Wheat and sorghum composite bread is brown with black and brown specks depending on the variety of sorghum flour used. Mochahlama has a welldistributed air cell (pores) structure and is not too crumbly. Compared to wheat bread, composite breads are always heavier with a dense texture. Cracks always appear on the top surface of mochahlama and they are perceived as an important quality attribute that indicates bread is indeed well cooked.

\section{Leavening agents}

Different leavening agents are used, such as sourdough [25]; traditional sorghum beer (tomoso ea joala) in different forms; beer foam (fresh foam or dried powdered foam, beer residue (moroko); modern beer (Hopose), sour porridge supernatant [(the liquid obtained from a fermented mixture of either maize and water or sorghum and water, prior to cooking sour porridge (tomoso ea motoho)]; and commercial yeast; a mixture of sourdough and commercial yeast. The choice of a raising agent was mainly based on availability and suitability. One participant said:

Leaving aside a small piece of dough from the previous fermented mixture makes the use of sourdough to be very convenient because no leavening agent has to be bought before preparing bread. Sourdough is a cheaper option for Basotho because it is not bought.

All participants agreed that commercial yeast is not suitable for composite, maize and sorghum breads according to the statement below:

Composite bread prepared from commercial yeast is tasteless; it lacks the sourness, which is the main characteristic of traditional Basotho composite bread. Commercial yeast also produces bread with a very loose texture.

\section{Preparing the steamer (Likaletsa)}

Basotho use available resources such as sticks, maize or sorghum stalks, wheat straw and grass in different regions for the steamer (Fig. 5). The technique for preparing the steamer involves:

Cleaning and sometimes peeling the sticks, then cutting them to the size of the pot. The sticks are arranged in a crisscross fashion in the middle of the pot to form a mesh-like structure. A thin layer of grass or wheat straw can then be rolled in circles over the sticks to allow enough space for the bread to rise to its maximum.

When wheat straws or grass are used on their own, a thick layer is rolled in circles inside the pot starting from the bottom of the pot up to the level that will allow dough to rise fully without touching the lid of the pot.

Steamer materials can be used on several occasions. They are kept in a safe place after use and are normally hung up on a tree and washed before the next use.

Participants in the urban areas use transparent plastic bags and sacks on top of grass or steamer wire. In South Africa, lower income families steam bread in a plastic bag [18] [17].

\section{Serving and consumption of bread in Basotho culture}

Traditional Basotho meal times were described by focus group participants in all regions as pleasant, sociable affairs. Male adults were served first and the food was taken outside to them while they were sitting close to their animals (khotla). Women ate inside the house while sitting flat on the ground or on a mat (moseme) prepared from grass (leloli), with their legs folded sideways under the body or their legs straightened out ( $b a$ namme). Children ate together from the same bowl while seated on the floor [4].

Bread was served in a conical-shaped Basotho basket (seroto) and an accompaniment served in a large enamel and/or steel bowl. However, if bread was to be eaten with milk, both bread and milk were mixed together (ho futsoela) in one bowl. Apart from milk, beans, peas, or boiled chicken, or mutton is commonly used in the rural areas to accompany bread. In the past, the Basotho portioned bread by breaking (hlephola) it with their hands, while nowadays, many families use knives to cut bread. 


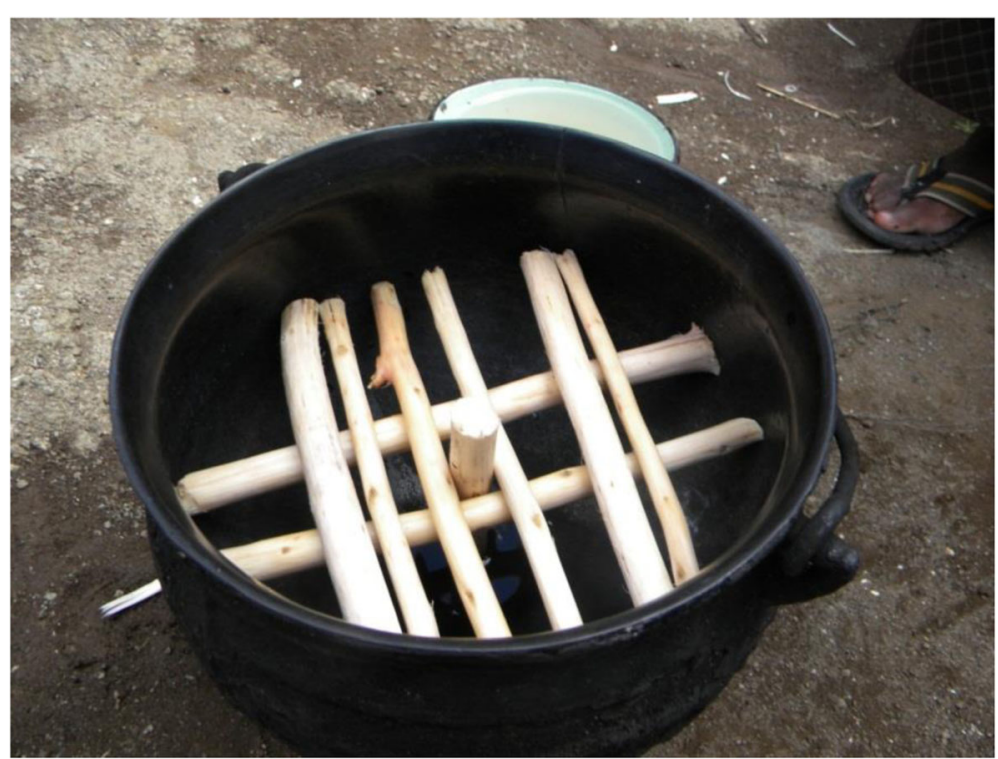

Fig. 5 Traditional Basotho bread steamer (Likaletsa) made from sticks. While all the other sticks are crossing each other in the pot, one stick protrudes to the top in the middle of the pot. This is done to allow steam to pass and to allow space for refilling with water. The middle stick also helps to create space between dough portions so that they remain separated for the steamed bread to cook faster. A thin layer of wheat straw or a layer of long grass is placed on top of sticks to prevent the dough from falling into the water.

The survey showed that baked bread was used for special occasions such as weddings and traditional feasts. Almost all (98\%, $n=248)$ used baked bread for trips and many $(96 \%, n=242)$ served baked bread on Christmas day. Others (94\%, $n=238)$ used baked bread for Moshoeshoes' day, feasts and for help teams (matsema) which happens spontaneously when neighbours come together to join hands to perform heavy duties like hoeing, harvesting, threshing and winnowing.

Bread has always played a major role in celebrations [4], as provision for students when they travel to visit other schools for sport and cultural dances during Moshoeshoe's Day. Steamed wheat bread was used more (81\%, $n=205$ ) for such trips than for other occasions. Moshoeshoe's day is celebrated in March every year across the country to remember the first Basotho king. This is part of the Basotho's long-standing heritage to honour the former King Moshoeshoe I who is the founder of the Basotho nation and who died on March 11,1870 . He is honoured for fighting against many nations in order to protect the land and the Basotho people, and also for preserving the country's language, art and culture.

It is a normal practice for Basotho children to wear new clothes and then move from one house to another on Christmas day to be served wheat bread, which is normally accompanied with a ginger cool drink. Wealthier families serve bread with chicken or mutton on Christmas day. According to participants, this practice encourages all Basotho to be generous from a very young age. One participant said:

Any woman who could not give children food, in particular bread, on a Christmas day was mocked and the whole village knew she was not a giver.

All the women in the village participated in preparation and baking wheat bread using mud ovens (onto) and sometimes flat cast iron pots for traditional feasts. One woman said:

When bread was prepared for traditional feasts, women would gather together to help with preparations and cooking of bread and that was where a woman who did not know how to prepare bread would be exposed.

Bread preparation was used as a test for newly married women (ngoetsi) as described in the making of polokoe. Similarly, a woman with poor cooking skills destroys the family's reputation and encounters serious marriage problems in relation to both the husband and the inlaws [26, 27].

Regardless of urbanization that changed culinary practices in Lesotho, the number of respondents who still prepare wheat breads for household consumption remains high for steamed $(98 \%, n=247)$, baked $(98 \%, n=$ $248)$ and pot-roasted bread $(68 \%, n=173)$, respectively. 
High popularity of wheat bread was confirmed by participants:

We like wheat bread so much, even more than meat. If it were possible I would not mind to eat wheat bread every day. Wheat bread is very special in our diet, it is not consumed as frequently as other food, it is prepared on Sundays and preparation of wheat bread requires a proper plan from the housewife (a 38-year-old woman).

Bread tastes good on its own and can even be consumed without any accompaniment and it can even go well with water (a 45-year old woman).

The main criterion for the Basotho's acceptance of bread is based on its perceived satiety value such that eating is not necessary for a while after consuming bread.

\section{Cultural related aspects to traditional Basotho bread} Elderly people eagerly mentioned that traditional Basotho bread forms part of Basotho tradition and culture. They all agreed that their mothers and grandmothers taught them the bread making skills at a very young age, because it was believed that a Mosotho woman should master the skills of producing bread with good sensory qualities as specified by the culture. Elderly people related the stories of their past on how traditional bread symbolises their culture. They had this to say:

When I grew up I thought my mother was very cruel when she taught me how to make different kinds of breads and insisted that I cannot make it in marriage if I do not master the bread-making skills. I enjoyed every moment of preparing and serving bread to my in-laws. My mother-in-law used to sit very close to me to watch while I was grinding grain, and wet milling on a grinding stone. I never had a problem with any of these processes of bread making.

\section{Conclusion}

Ten different types of traditional Basotho breads, prepared from maize, wheat and sorghum were identified in this paper and shown as differing in terms of culinary practices, physical and sensory properties. The most common method of cooking for all breads is steaming. Baking and pot-roasting are used to cook wheat breads only. The longer and tedious processes involved in the preparation of traditional Basotho breads calls for an investigation into how the people of Lesotho could be helped with labour saving, affordable equipment and technologies that apply and hence encourage the use of whole grain flours rather than refined commercial flours for making bread. The findings of this study help to understand and interpret the overall scope of Basotho attitude towards breads for the maximum utilisation of local grains in Lesotho. It also adds the Basotho perspective of cultural food acceptance to the existing global knowledge of food choice regarding traditional and ethnic food products.

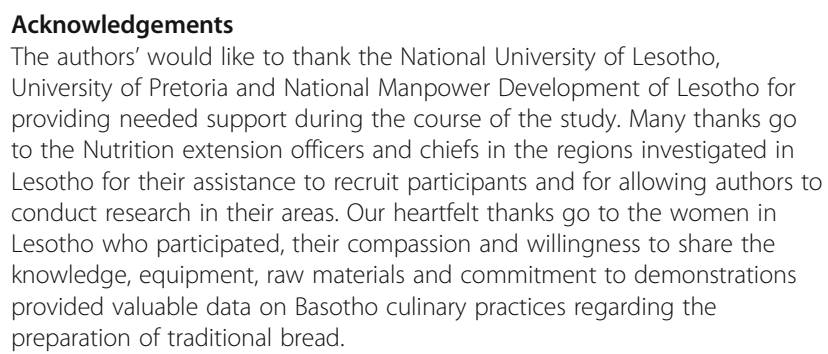

\section{Authors' contributions}

PN, GR and RK conceived the project and the main conceptual ideas and designed the model of carrying it out. PN developed the interview schedule for focus groups and the questionnaire for quantitative data collection under the supervision of GR and RK. PN carried out the survey and took the lead in writing the manuscript. All authors provided critical feedback and helped shape the research, analysis of results and conclusion of manuscript. All authors read and approved the final manuscript.

\author{
Authors' information \\ Corresponding author \\ Dr. P. Nkhabutlane (was a PhD student while the study was being \\ conducted) \\ Lecturer Consumer Science, National University of Lesotho \\ P.O.Box 180 Roma, Lesotho \\ Tel: $+26652200000 /+26652213000$ \\ Cell No:+266 58997109 \\ Fax: +26622340000 \\ Email: pn111@hotmail.com;p.nkhabutlane@nul.Is \\ Website: http:/www.nul.ls \\ Prof. $\mathrm{H} L$ de Kock (was the co-supervisor) \\ Associate Professor Dept of Consumer \& Food Science, University of Pretoria \\ Private Bag X20 Hatfield, Pretoria 0028, South Africa \\ Tel: +27 124203238 Fax: +27 124202839 \\ Prof. GE Rand (was the main supervisor) \\ Associate Professor Dept Consumer and Food Sciences, University of Pretoria \\ Faculty of Natural and Agricultural Sciences \\ University of Pretoria, Private Bag X20 \\ Hatfield 0028, South Africa
}

\section{Funding}

This research did not receive any specific grant from funding agencies in the public, commercial, or not-for-profit sectors.

\section{Availability of data and materials \\ Mendeley data}

\section{Competing interests}

The authors declare that they have no competing interests.

Received: 1 February 2019 Accepted: 6 September 2019

Published online: 24 October 2019

\section{References}

1. FAO/WFP. Crop and food supply assessment mission. http://www.fao.org/ giews/ (2007). Accessed 21 Jan 2013.

2. Agricultural Situation Report 2005/06-2006-07. Maseru, Lesotho. Ministry of Agriculture and Food Security. 2008. Lesotho. 
3. Wansink B, Sonka S, Cheney M. A Cultural hedonic framework for increasing the consumption of unfamiliar foods: soy acceptance in Russia and Colombia. Rev. Agric. Econ. 2002;24:353-65.

4. Ashton EH. A sociological sketch of Sotho diet. Transactions of the Royal Society of South Africa. 1939;27:147-214.

5. Raschke V, Oltersdorf U, Elmadfa I, Wahlqvist ML, Kouris-Blazos A, BSB C. The need for an online collection of traditional African - food habits. Afr J Food Agric. Nutr Dev. Online Version. 2007:1684-5374.

6. Gisslen W. Professional baking. 5th ed. New Jersey: World Scientific; 2009

7. Osseo-Asare F. Food culture in sub-Saharan Africa. Westport: Greenwood Press; 2005.

8. Creswell JW. Designing and conducting mixed methods research. 2nd ed. United States: Sage publications; 2011.

9. Babbie E, Mouton J. The basics of social research. 3rd ed. Cape Town: Oxford University Press; 2002

10. De Vos AS, Strydom H, Fouche CB, Poggenpoel M, Schurink EW. Research at grass roots. 3rd ed. Pretoria South Africa: Van Schaik Publishers; 2001.

11. Krueger RA. Focus groups - a practical guide for applied research. 4th ed. Thousand Oaks: Sage; 2009.

12. Bouthyette PY. Fermentation. T1 documents. 2008. http://www. chemistrywithdrb.com/files/Fermentation.pdf. Accessed 25 Jan 2013

13. Wen QB, Lorenz KJ, Martin DJ, Stewart BG, Sampson DA. Carbohydrates digestibility and resistant starch of steamed bread. Starch - Starke. 1996;48:180-5.

14. Ang CYM, Liu K, Huang YW. Asian foods. Science and Technology 1st ed. United States: Technomic Publishing CO. Inc; 1999.

15. Rubenthaler GL, Huang ML, Pomeranz Y. Steamed bread - Chinese steamed bread formulation and interactions. Cereal Chem. 1990;67:471-5.

16. Sun M. Compare the steamed bread made from starter with the one from yeast. Hot Spot and Research. 2007;25:18-9.

17. Lombard GE, IAG W, Minnaar A, Taylor JRN. Preservation of South African steamed bread using Hurdle Technology. Food Sci. Technol. 2000. https:// doi.org/10.1006/fstl.1999.0626.

18. Manley M, Nel MM. Investigation of the suitability of Western and Southern Cape wheat flour for production of traditional South African steamed bread. S Afr Tydskr. Plant Grond. 1999;16:135-42.

19. Nout MJR. Rich nutrition from the poorest - cereal fermentation in Africa and Asia. Food Microbiol. 2009;26:685-92.

20. Nche PF, Odamttent GT, Nout MJR, Rombouts FM. Soaking of maize determines the quality of Aflata for kenkey production. J Cereal SCI. 1996;24:291-7.

21. Nout MJR, Kok B, Vela E, Nche PF, Rombouts FM. Acceleration of the fermentation of kenkey, an indigenous fermented maize food of Ghana. Food Res Int. 1996;28:599-604.

22. FAO. Food security information for decision making. WWW.foodsec.org (2011). Accessed Nov 2012

23. Tsikoane T, More than bread flour - towards a social history of grain milling in Lesotho. S Afr Hist J. 200758:277-296.

24. Quin PJ. Foods and feeding habits of the Pedi. S Afri. Med J. 1964:38:969-71.

25. Moroni AV, Dal Bello F, Arendt EK. Sourdough in gluten-free breadmaking - an ancient technology to solve a novel issue? Food Microbiol. 2009;26:676-84

26. Elwert-Kretschmer K. Culinary innovation, love, and the social organization of learning in a West African city. Food \& Foodways J. 2001. https://doi.org/ 10.1080/07409710.2001.9962112.

27. Sharf BF, Sukovic M, Sharkey JR, John J. Seasoning for the soul: empowerment through food preparation among Mexican women in the Texas Colonias. Food \& Foodways J. 2011;19:228-47.

\section{Publisher's Note}

Springer Nature remains neutral with regard to jurisdictional claims in published maps and institutional affiliations.

Ready to submit your research? Choose BMC and benefit from:

- fast, convenient online submission

- thorough peer review by experienced researchers in your field

- rapid publication on acceptance

- support for research data, including large and complex data types

- gold Open Access which fosters wider collaboration and increased citations

- maximum visibility for your research: over $100 \mathrm{M}$ website views per year

At $\mathrm{BMC}$, research is always in progress.

Learn more biomedcentral.com/submissions 